\title{
On the Effectiveness of Liability Rules when Agents are not Identical
}

\author{
WINAND EMONS \\ University of Basel \\ and \\ JOEL SOBEL \\ University of California, San Diego
}

First version received August 1988; final version accepted August 1990 (Eds.)

\begin{abstract}
This paper is about accidents involving two risk-neutral parties. Both parties engage in actions that are profitable but affect the magnitude of possible bilateral accidents. We analyse how the action choices can be decentralized by liability rules that assign the accident costs to the two parties. If we allow for punitive damages, we can implement the first-best actions by a liability rule even if agents are not identical. Under this liability rule some individuals may be in expectation better off in the event of an accident than in the event of no accident. We provide conditions under which this problem does not arise.
\end{abstract}

\section{INTRODUCTION}

This paper studies bilateral accidents. The people involved in an accident, injurers and victims who may be thought of as motorists and bicyclists, must each decide which action to take when engaging in an activity. Taking a high action may be profitable, but it increases the magnitude or probability of accidents. We are interested in learning how effective legal rules that allocate costs of accidents on the basis of observed actions can be in encouraging agents to make efficient choices.

Our problem has been thoroughly studied in situations where all injurers, as well as all victims, are identical. Shavell (1987) describes this work. In this identical-agents setup, research has concentrated on liability rules that encourage all injurers, as well as all victims, to take the same (efficient) action. One way to attain the efficient choices is to use a negligence rule. A negligence rule holds injurers strictly liable so that they pay the full amount of damages if they exceed the efficient due action level; otherwise, they are not liable. In order not to be liable, injurers engage in the efficient due action level. Given the injurers' behaviour, victims are, therefore, strictly liable in the event of an accident. As a result, they too will take the efficient action level.

The negligence rule is simple and, in the identical agents case, effective. Nevertheless, it is no longer effective when parties differ from each other. We concentrate on situations where both injurers and victims differ among themselves in the benefit from taking the action. When we relax the identical agents assumption, efficiency will typically require that different agents take different actions. Efficiency requires that a doctor rushing to 
see a patient in the emergency room be allowed to drive faster than a professor trying to arrive at the university for a second cup of coffee before class begins. The example suggests a solution to the problem. If the legal rules could depend on preferences of the injurer, or perhaps even on observable characteristics, like profession, age, or race, then it may be possible to adjust the due action level in the negligence rule to the kind of injurer involved in an accident. Indeed, general rules of this sort are possible, for example, the negligence rule using the incremental Learned Hand formulation. (See Posner (1986), pp. 151-152.)

We prefer to concentrate on legal rules that depend on less information. Specifically, information about the preferences may not be known to the judicial system. If we assume that the courts cannot discover the agents' utility functions, then we must limit attention to liability rules that depend only on the choices of the parties involved in an accident. Even if the court knows the agents' preferences or uses rules that depend only on observable characteristics, we wish to avoid liability rules that treat two accidents involving agents taking identical action levels differently. That is, we do not want the professor to pay more when he is in an accident simply because he is not a medical doctor. If equal protection means that everyone doing the same thing in the same situation should be treated in the same way, then we are again constrained to use liability rules that depend only on the action choices of the participants in an accident.

In this paper we show that it is possible to find a liability rule, which depends only on action levels, that induces everyone to choose the efficient actions. The rules are more complicated than the negligence rules that work in the identical-agents model, but they do not require the courts to use information about individual preferences in assigning liability.

If a liability rule is to induce actors to make efficient choices, then they must be forced to bear the social cost of their behaviour. The liability rules that we describe in Section IV have this property. The change in damages caused by a change in the action is precisely reflected in the change of the corresponding liability payment. We derive schemes that have this property from similar rules proposed by d'Aspremont and GérardVaret (1979) for a slightly different class of problems. It should be clear that the rules must do more than allocate a fixed share of the accident costs to injurer and victim independent of the action levels that they select. Such a rule would not internalize the social cost of choosing an action. Instead, the rules are the sum of three terms. The first term is a share of actual damages. The second term depends only on the action of the injurer. It can be thought of as measuring damages that the injurer would expect to cause before knowing the victims' action levels. These two terms can be adjusted so that the expected damage payment of the injurer is equal to the social damage that he causes. The third term depends only on the victim's action choice. As far as the injurer is concerned, the term is constant but it can be selected to guarantee that the victim's expected damage payment is equal to the social damage that he causes.

From another point of view, the problem of finding liability rules that decentralize the efficient action levels is easy. One could charge both parties involved in any accident the full amount of the damages. With a rule of this sort, agents must pay the full social cost of their actions; they have proper incentives to make the efficient choices. We do not consider this type of rule because it requires total damage payments to exceed the actual damages. We require that the total payments of the participants to an accident equal the total amount of damage done. An agent's payment may be negative, however. In certain situations punitive damages, damage payments that exceed the actual cost of the accident, are needed; in these cases the other party receives a reward for being in an 
accident. While it is not possible to implement the efficient action levels without using punitive damages, punitive damages in expectation, i.e. expected payments that exceed expected damages, are not used in the liability rules that we construct.

Although there is no reason for agents to pay punitive damages in expectation, the liability rules that we construct have one defect. Under the rules some individuals may ex ante expect to be better off in the event of an accident than if they do not get into an accident. In other words, in order to implement the first-best choice of action levels some agents might be rewarded ex ante for being involved in an accident. We view this as a critical defect. Allowing expected rewards creates incentives for certain agents to increase the likelihood of accidents, or for other agents who receive no utility from the activity to participate in the hope of being in an accident. While these factors are beyond the scope of our formal model, we think that it is important to describe those behaviours that can be implemented without expected rewards. In order to do this completely, we make further assumptions on preferences, basically, that the action is a single variable and that different agents can be ordered according to their marginal utility from taking the action. Under these conditions, we can completely characterize the set of actions that can be implemented by liability rules. We characterize the subset of action levels that can be implemented without expected rewards.

The remainder of the paper is organized as follows. Section II outlines the general model. In Section III we present an example that gives the flavour of our general results. Section IV contains a description of the simple liability rules derived from d'Aspremont and Gérard-Varet. Proposition 1 demonstrates that these rules can decentralize the efficient actions without using expected punitive damages; we conclude Section IV with a discussion of the work of d'Aspremont and Gérard-Varet. In Section V we make further assumptions on preferences and characterize the set of action levels that can be implemented without expected rewards. Section VI contains a more detailed discussion of the relationship between our results and the law and economics literature. Section VII is a brief conclusion. Technical discussions are confined to the end of Section IV, Section V, and the Appendix.

\section{THE MODEL}

Consider an economy where accidents involving two kinds of parties, injurers and victims, may occur. Each injurer $i, i=1, \ldots, r$, engages in an action level $x \in S$. An action level $x$ generates monetary utility $U_{i}(x)$ for injurer $i$. Victim $j, j=1, \ldots, r$, chooses an action level $y \in T$ that yields monetary utility $V_{j}(y)$. In Section $V$ we assume that action levels are real numbers selected from a compact interval and we make further assumptions on preferences. The liability rules that we describe in Section IV apply to general situations. In particular, an action may be a vector describing, e.g. an activity level and a level of care.

Let $p(x, y) \geqq 0$ denote the expected monetary loss from an accident involving an injurer at action $x$ and a victim at action $y$. The quantity $p(\cdot)$ takes into account the effects action levels have on both the probability and the magnitude of an accident. That is, $p(x, y) \equiv \pi(x, y) P(x, y)$ where $\pi(x, y)$ denotes the probability of an accident and $P(x, y)$ the actual loss given action levels $x$ and $y$. We assume that damages depend only on the action choices of the parties involved in an accident and not on other characteristics of the victim or injurer. The expected harm associated with injurer $i$ is $\sum_{j} p\left(x_{i}, y_{j}\right)$ and with victim $j$ accordingly $\sum_{i} p\left(x_{i}, y_{j}\right)$. Note that although we refer to the two parties as injurers and victims, this does not necessarily imply that victims experience the loss in the absence of legal rules. Injurers, a third party, even any combination of all individuals 
in the society may suffer from the loss. The damage $p(\cdot)$ constitutes a loss for the economy we analyse.

Denote the injurers' action levels by $X=\left(x_{1}, \ldots, x_{r}\right)$ and the victims' action levels by $Y=\left(y_{1}, \ldots, y_{r}\right)$. We measure efficiency by the utilitarian welfare function

$$
W(X, Y)=\sum_{i} U_{i}\left(x_{i}\right)+\sum_{j} V_{j}\left(y_{j}\right)-\sum_{i} \sum_{j} p\left(x_{i}, y_{j}\right)
$$

We assume that $W(\cdot)$ has a maximizer $\left(X^{*}, Y^{*}\right)$ with $X^{*}=\left(x_{1}^{*}, \ldots, x_{r}^{*}\right)$ and $Y^{*}=$ $\left(y_{1}^{*}, \ldots, y_{r}^{*}\right)$; we call these action levels first-best. Observe that if $\left(X^{*}, Y^{*}\right)$ are first-best action levels, then for each $i, x_{i}^{*}$ maximizes $U_{i}(x)-\sum_{j} p\left(x, y_{j}^{*}\right)$, and for each $j, y_{j}^{*}$ maximizes $V_{j}(y)-\sum_{i} p\left(x_{i}^{*}, y\right)$.

As an example think of injurers as car drivers and of victims as bicyclists. Both parties choose the speed at which they travel. Drivers and bicyclists like to speed. The faster both parties go, the higher the expected loss from an accident. Economic efficiency requires that drivers (bicyclists) with low marginal utility travel at a lower speed than drivers (bicyclists) with high marginal utility.

In the absence of legal rules each individual maximizes the utility out of its respective action minus the expected accident cost it has to bear. If the bicyclists incur the entire damages, all car drivers obviously go as fast as possible. If a third party suffers from the loss, both all drivers and all bicyclists travel at maximum speed. Consequently, there is typically a need for a mechanism that decentralizes the action choices in an efficient way.'

\section{AN EXAMPLE}

In this section we present a simple version of the above example to give a flavour of our general results. We assume that there are two drivers and two bicyclists. For $i \in\{1,2\}$, driver $i$ generates monetary utility $U_{i}(x)=i x$ when she drives at speed $x$. Symmetrically, for $j \in\{1,2\}$ bicyclist $j$ generates monetary utility $V_{j}(y)=j y$ when he pedals at speed $y$. Assume that expected damages caused by an accident depend on the sum of the speeds of colliding people, $p(x, y)=F(x+y)$. In our exposition we assume that agents can pick speed either 0 or 1 , and that $F(0)=c, F(1)=\frac{1}{4}+c$, and $F(2)=\frac{5}{4}+c$.

We want to show how liability rules could be used to decentralize the choice of speed levels $\left(X^{*}, Y^{*}\right)=(0,1,0,1)$ where the agents who get geater utility from speed go fast, but the other agents go slowly. It is sensible to encourage a driver to set $x_{i}=0$ if $i=1$ and $x_{i}=1$ if $i=2$ and for bicyclists to behave in a similar fashion. Indeed, these speed levels maximize the utilitarian welfare function $W(\cdot)$. So our problem is to design an incentive scheme that encourages type 1 individuals to operate at a lower level than type 2 individuals.

A liability rule prescribes how much of an actual loss has to be borne by the injurer and the victim. We will identify a liability rule by the part of the expected loss $l(x, y)$ the injurer bears. Actual damage payments in the event of an accident are thus the amount $l(x, y)$ divided by the probability of an accident $\pi(x, y)$ given $x$ and $y$. Under the liability scheme $l(\cdot)$ the victim bears $p(x, y)-l(x, y)$. Therefore, we confine our attention to liability rules where a loss is entirely split up between the injurer and the victim. We do not restrict the range of $l(\cdot)$; an injurer may end up paying punitive damages $l(x, y)-p(x, y)>0$ while the corresponding victim is rewarded by this amount

1. Other examples abound. The probability and/or the degree of oil spills may depend on the speed at which ships use a sea lane. How carefully ice is cleared from sidewalks and the amount of foot traffic determine the number of broken legs. The number of hunting accidents depends on the amount of hunting and hiking in a forest. 
and vice versa. When $x$ and $y$ may take only the values 0 and 1 , a liability rule specifies just four numbers: $l(0,0), l(0,1), l(1,0)$, and $l(1,1)$.

We want to construct a liability rule that makes it in the best interest for $i=1$ to pick $x=0$ and $i=2$ to pick $x=1$. A driver's choice of speed plainly depends on how fast bicyclists choose to go. We concentrate on Nash equilibria. So we must guarantee that it is optimal for drivers to choose $X^{*}=(0,1)$ given that bicyclists pick $Y^{*}=(0,1)$. Assume that the bicyclists pick $Y^{*}=(0,1)$. If a driver decides to choose $x=0$, then expected damages from her behaviour are $p(0,0)+p(0,1)=2 c+\frac{1}{4}$. Similarly, if she selects speed $x=1$, then expected damages from her behaviour are $p(1,0)+p(1,1)=2 c+\frac{3}{2}$. Hence, the increase in damages is $\frac{5}{4}$. If we could design a liability rule that had the property that expected liability payments associated with choosing $x=1$ are $\frac{5}{4}$ greater than those payments when $x=0$, then we can be sure that drivers make the efficient choices of action: They would choose to speed exactly when the monetary utility of doing so compensated for the marginal social damage they cause. It is not hard to find a rule that does this. For example, let

$$
l(x, y)=\frac{1}{2} p(x, y)+\frac{1}{4}[p(x, 0)+p(x, 1)]-\frac{1}{4}[p(0, y)+p(1, y)]=\frac{1}{2} p(x, y)+\frac{5}{16} x-\frac{5}{16} y .
$$

The quantity that is relevant to the decision of the driver is the sum $l(x, 0)+l(x, 1)$ because a type one bicyclist picks $y=0$ and a type two bicyclist picks $y=1$. The sum is

$$
c+\frac{5}{4} x-\frac{3}{16} \text {. }
$$

The formula has precisely the property we wanted: increasing $x$ from 0 to 1 increases the liability of the driver by $\frac{5}{4}$. Consequently, the type one driver will pick $x=0$ and the type two driver will pick $x=1$. A symmetric argument establishes that the bicyclists, faced with the same liability rule and under the assumption that drivers pick $X^{*}=(0,1)$, will respond optimally by picking $Y^{*}=(0,1)$.

The formula has an additional useful property that we did not impose. The damages that the driver expects to cause are equal to $2 c+\frac{1}{4}+\frac{5}{4} x$, which always exceed the amount in (1). Consequently, the driver is not asked to pay more in expectation than the damage associated with her behaviour. In this case, we say that the driver does not pay punitive damages in expectation. Again, the same property holds for bicyclists. We could ask even more of a liability scheme. Our construction does not guarantee that actual damages exceed actual payments. To rule out (actual) punitive damages requires that $0 \leqq l(x, y) \leqq$ $p(x, y) \forall x, y$. Unless $c \geqq \frac{3}{8}$, however, the scheme described above requires the use of punitive damages in some contingencies. For example, the driver must pay punitive damages when she picks $x=1$ and the cyclist picks $y=0$. We see no reason to rule out punitive damages and allow them throughout the paper.

Proposition 1 demonstrates that these properties are general. We describe a liability rule, actually a family of rules, that is always able to implement the first-best action levels without punitive damages in expectation. The liability of the driver is the sum of three terms: a fraction of the actual damages, a term that does not depend on the cyclist's action, and a term that does not depend on the driver's action. It is possible to pick the second term in such a way that any change in the action level leads to a change in liability that equals the actual change in damages. It is possible to pick the third term so that there are no expected punitive damages. The rules we present are motivated by incentive schemes used by d'Aspremont and Gérard-Varet (1979) in a related setting.

The liability rule described above encourages agents to make the welfare-maximizing choices. However, it is not entirely satisfactory in another respect. It would be a good idea to look for liability rules that have non-negative expected payments for any type of 
agent. For example, if the quantity (1) is negative, then a driver would expect to be rewarded for getting into an accident. If rewards of this kind were offered, then there would be incentives for socially inefficient "entry" of non-drivers, who would drive in the hope of getting into accidents. If a driver selects $x=0$, then expected damage payments are $c-\frac{3}{16}$ by (1). Consequently, unless $c \geqq \frac{3}{16}$ the liability rule described above does not implement the efficient actions without expected rewards. In general, it is not possible to implement without expected rewards unless total damages are large-reflected in the example by high values of $c$. There is no liability rule that implements without expected rewards when $c<\frac{1}{16}{ }^{2}$

It is possible to improve upon the performance of the rule given above in certain circumstances. If $\frac{1}{16} \leqq c<\frac{3}{16}$, there exist liability rules that implement without expected rewards. The liability rule we have described has the property that an incremental change in an agent's payment from changing an action level is exactly equal to the change in expected damages induced by the agent's change in action. This condition is sufficient to implement the first-best actions. Yet it is not a necessary condition. In the example, a type 1 driver will not pick action level 1 if liability payments increase by 1 or more when she does so. Using liability rules in which the incremental payment for choosing the higher speed is 1 instead of $\frac{5}{4}$ gives us the flexibility to implement more action levels without expected rewards. The liability schemes constructed in Section V take advantage of this flexibility. That is what distinguishes them from the scheme introduced above and analysed in detail in the next section.

\section{DECENTRALIZING THE ACTION CHOICE BY LIABILITY RULES}

In this section we demonstrate that a variation of an incentive scheme proposed by d'Aspremont and Gérard-Varet (1979) implements the first-best actions.

We say that the liability scheme $l(\cdot)$ as defined in Section III implements the action levels $\left(X^{*}, Y^{*}\right)=\left(\left(x_{1}^{*}, \ldots, x_{r}^{*}\right),\left(y_{1}^{*}, \ldots, y_{r}^{*}\right)\right)$ if and only if $\left(X^{*}, Y^{*}\right)$ is a Nash equilibrium to the game in which each party simultaneously picks action levels and pays damages according to the scheme $l(\cdot) .^{3}$ Formally, $\left(X^{*}, Y^{*}\right)$ satisfy

$$
U_{i}\left(x_{i}^{*}\right)-\sum_{j} l\left(x_{i}^{*}, y_{j}^{*}\right) \geqq U_{i}(x)-\sum_{j} l\left(x, y_{j}^{*}\right) \quad \forall x \in S, \quad i=1, \ldots, r,
$$

and

$$
\begin{gathered}
V_{j}\left(y_{j}^{*}\right)-\sum_{i}\left[p\left(x_{i}^{*}, y_{j}^{*}\right)-l\left(x_{i}^{*}, y_{j}^{*}\right)\right] \geqq V_{j}(y)-\sum_{i}\left[p\left(x_{i}^{*}, y\right)-l\left(x_{i}^{*}, y\right)\right] \\
\forall y \in T, \quad j=1, \ldots, r .
\end{gathered}
$$

We say that no agent pays expected punitive damages under the liability scheme $l(\cdot)$ if for all $i, \sum_{j}\left[p\left(x_{i}^{*}, y_{j}^{*}\right)-l\left(x_{i}^{*}, y_{j}^{*}\right)\right] \geqq 0$, and for all $j, \sum_{i} l\left(x_{i}^{*}, y_{j}^{*}\right) \geqq 0$. Ruling out expected punitive damages is necessary if we cannot force an agent to a utility level lower than

2. If $c<\frac{1}{16}$, then it is not possible to implement the efficient actions without expected rewards. To see this, observe that if $l(\cdot)$ implements the first-best without expected rewards, it must satisfy: $l(0,0)+l(0,1) \geqq$ $0, l(0,0)+l(0,1) \leqq l(1,0)+l(1,1)-1, l(0,0)+l(1,0) \leqq p(0,0)+p(1,0)$, and $p(0,0)-l(0,0)+p(1,0)-l(1,0) \leqq$ $p(0,1)-l(0,1)+p(1,1)-l(1,1)$. The first inequality states that the type-one driver does not receive an expected reward; the second inequality guarantees that he picks $x=0$; and the third and fourth inequalities say that the type-one cyclist receives no reward and weakly prefers $y=0$ to $y=1$. It is straightforward to show that there exist liability rules $l(\cdot)$ that satisfy these inequalities if and only if $c \geqq \frac{1}{16}$.

3. Note that we do not require that these action levels are unique Nash equilibria for the game induced by the liability rule $l(\cdot)$. We have no reason to believe that the game has a unique equilibrium. Techniques developed for slightly different problems (see Ma, Moore, and Turnbull (1988) and Moore and Repullo (1988)) may solve the multiple-equilibrium problem in our setting. 
he would get if he were responsible for all the damages associated with his behaviour. Moreover, a liability rule that uses expected punitive damages may violate legal opinions about fairness. Our first result states that we may implement the first-best action levels without expected punitive damages using simple liability rules. rule

Proposition 1. Suppose there exists a first-best allocation $\left(X^{*}, Y^{*}\right)$. Then the liability

$$
l(x, y)=d p(x, y)+(1-d) / r \sum_{j} p\left(x, y_{j}^{*}\right)-d / r \sum_{i} p\left(x_{i}^{*}, y\right)
$$

with $d \in(0,1)$ implements $\left(X^{*}, Y^{*}\right)$ and no agent pays expected punitive damages.

Proof. Suppose victims pick $Y^{*}$. Then injurer $i, i=1, \ldots, r$, maximizes

$$
U_{i}(x)-\sum_{j} l\left(x, y_{j}^{*}\right)=U_{i}(x)-\left[\sum_{j} p\left(x, y_{j}^{*}\right)-d / r \sum_{i} \sum_{j} p\left(x_{i}^{*}, y_{j}^{*}\right)\right]
$$

which is obviously maximized by $x_{i}^{*}, i=1, \ldots, r$.

Analogously, given injurers pick $X^{*}$, victim $j, j=1, \ldots, r$, maximizes

$$
V_{j}(y)-\sum_{i}\left[p\left(x_{i}^{*}, y\right)-l\left(x_{i}^{*}, y\right)\right]=V_{j}(y)-\left[\sum_{i} p\left(x_{i}^{*}, y\right)-(1-d) / r \sum_{i} \sum_{j} p\left(x_{i}^{*}, y_{j}^{*}\right)\right]
$$

which is maximized by $y_{j}^{*}, j=1, \ldots, r$.

Next note that

$$
\sum_{j} l\left(x_{i}^{*}, y_{j}^{*}\right)+\sum_{i}\left[p\left(x_{i}^{*}, y_{j}^{*}\right)-l\left(x_{i}^{*}, y_{j}^{*}\right)\right]=\sum_{i} \sum_{j} p\left(x_{i}^{*}, y_{j}^{*}\right),
$$

i.e. the agents' liability payments add up to total damages.

Finally, notice that $\sum_{j} l\left(x_{i}^{*}, y_{j}^{*}\right) \leqq \sum_{j} p\left(x_{i}^{*}, y_{j}^{*}\right)$ as well as $\sum_{i}\left[p\left(x_{i}^{*}, y_{j}^{*}\right)-l\left(x_{i}^{*}, y_{j}^{*}\right)\right] \leqq$ $\sum_{i} p\left(x_{i}^{*}, y_{j}^{*}\right)$. That is, no individual pays more in expectation than the expected harm associated with its action or, put differently, no agent pays expected punitive damages.

The liability rule used in Proposition 1 has three terms. The first term allocates to the driver a fraction $d$ of the damages. The second term depends on the action level of the driver (who chooses $x_{i}$ ) but not on the bicyclist (who chooses $y_{j}$ ). The third term does not depend on the driver's action level. The family of liability rules decentralizes the first-best allocation because the driver's expected payment given that cyclists pick the first-best actions is the expected damages caused by selecting action level $x, \sum_{j} p\left(x, y_{j}^{*}\right)$, minus a positive constant. Consequently, the rule fully captures the externality created by bilateral accidents. The only assumption needed on preferences and damages for the rule to work is that first-best action levels exist. In particular, there is no need to assume that actions are one-dimensional.

The strength of Proposition 1 may be surprising. Indeed, Shavell (1980) considers a setup where an injurer and a victim pick a care and an activity level so that $x, y \in \mathbb{R}_{+}^{2}$. He shows that there does not exist an efficient liability rule that depends only on the victim's actual loss and the two care levels. There is no conflict between this result and Proposition 1. The power of the proposition stems from the assumption that the court can observe and use the information in all components of $x$ and $y$ in order to compute damages. If the judge could condition payments on both activity and care levels in Shavell's model, then our result would imply that efficient liability rules exist.

Our results are related to d'Aspremont and Gérard-Varet (1979). To make a comparison, we formulate our model in the language of Bayesian incentive problems (see, e.g. Myerson (1985)). There are two agents, an injurer and a victim. There is one type of agent for each possible preference, a total of $r$ types of each agent. Each agent has beliefs about the other type of agent. We assume that an agent believes the types of the 
other agent are equally likely. This corresponds to our assumption that there is precisely one injurer and one victim of each type. A Bayesian mechanism consists of a central authority who asks each agent to report its type. In response to the reported types, the centre recommends actions to both agents. It also selects a liability rule which can depend on the reports and actions selected by the agents. d'Aspremont and Gérard-Varet have identified conditions under which the central authority can implement the first-best actions. Their most important assumption, that agents' preferences are quasi-linear, is satisfied in our model. If our model were a special case of theirs, then we could apply their result to prove that the first-best actions $\left(X^{*}, Y^{*}\right)$ could be implemented.

There are two reasons why we cannot apply the results of d'Aspremont and GérardVaret directly. First, in their setup, the central authority selects action levels as a function of reported types. In our model, the agents pick their own action level. Yet this difference is not important. We can imagine that the central authority recommends an action level to each agent. Agents need not follow the authority's recommendation; however, the centre can make liability rules depend on whether or not the agents follow its recommendation. It is not difficult to construct rules that make it an equilibrium for agents to always follow the centre's recommendation. These rules could assign full liability to an agent who selected action levels different from what the centre recommended.

The second difference is that in d'Aspremont and Gérard-Varet the liability rule and recommended actions can depend on the reported types of the agents, not only on their action levels. Consequently, the centre is able to recommend a different action to the victim for each possible injurer. If we allowed this type of dependence in our example, then a motorist's recommended speed would depend not only on her preferences, but also on the preferences of the cyclist she runs into. Allowing the centre to condition its recommendation on the reported types of agents assumes that the centre may use information about the precise victim-injurer pair involved in an accident. In principle, the centre could ask a driver to choose a different speed level depending on the reported identity of the victim. Liability rules would then implement a collection $\left(x_{i j}, y_{i j}\right)$, where $x_{i j}$ is interpreted as the speed of driver $i$ when bicyclist $j$ is around. If liability rules of this sort were feasible, then the results of d'Aspremont and Gérard-Varet would show that it is possible to decentralize action levels that are "better" than what we call first-best. Not only would drivers of different types be allowed to go at different speeds, but they would also be given incentives and information to drive differently depending on whom they might run into. It does not make sense to allow an agent's speed to depend on the reported type of the other agent. In our model liability rules depend only on observed actions. Since the actions recommended to a driver are allowed to depend on more information (the reported type of the bicyclist in addition to the reported type of the driver), more rules are feasible in d'Aspremont and Gérard-Varet; they are able to implement a different class of action levels. Their results do not directly apply to our model. Nevertheless, the rules proposed in Proposition 1 are precisely the d'Aspremont and Gérard-Varet rules specialized to our framework.

We close this section with a technical note. The results in Proposition 1 can be strengthened with no additional assumptions. Call the action levels $\left(X^{*}, Y^{*}\right)$ restricted optimal if

$$
\begin{aligned}
& i \text { solves } \max _{1 \leqq k \leqq r} U_{i}\left(x_{k}^{*}\right)-\sum_{j} p\left(x_{k}^{*}, y_{j}^{*}\right), \quad i=1, \ldots, r, \\
& j \text { solves } \max _{1 \leqq l \leqq r} V_{j}\left(y_{l}^{*}\right)-\sum_{i} p\left(x_{i}^{*}, y_{l}^{*}\right), \quad j=1, \ldots, r .
\end{aligned}
$$

Action levels are restricted optimal if social welfare cannot be increased if one type selects an action level specified for another type instead of the action level specified for 
him/her. Action levels that specify a constant action level for each type are automatically restricted optimal. Also first-best action levels are restricted optimal. The importance of the definition is that any restricted optimal action levels can be implemented without expected punitive damages. To see this, call an action level 'strange' if it is not specified for any type. Modify the rules in Proposition 1 so that if an agent selects a strange action (but the other agents behave as specified by the equilibrium), then the deviant agent must pay a large amount. With this change, it is never in the interest of anyone to choose a strange action. An examination of Proposition 1 shows that restricted optimality is sufficient to show that each tvpe would in fact wish to select the action specified for $\mathrm{him} / \mathrm{her}$ rather than an action recommended to another type.

\section{IMPLEMENTATION WITHOUT EXPECTED REWARDS}

One limitation of the incentive scheme described in Proposition 1 is that parties may ex ante expect a reward for being involved in accidents. That is, there is no guarantee that there exists $d \in(0,1)$ such that for all $i, \sum_{j} p\left(x_{i}^{*}, y_{j}^{*}\right)-d / r \sum_{i} \sum_{j} p\left(x_{i}^{*}, y_{j}^{*}\right) \geqq 0$, and for all $j, \sum_{i} p\left(x_{i}^{*}, y_{j}^{*}\right)-(1-d) / r \sum_{i} \sum_{j} p\left(x_{i}^{*}, y_{j}^{*}\right) \geqq 0$.

In this section we describe action levels that can be implemented with non-negative expected payments. There are two reasons for imposing this restriction. First, imagine in terms of our example that there is a pool of people who do not enjoy the activity, but would participate in it if they gained by doing so. Formally, we could assume that there was an unlimited amount of type $i=0$ motorists such that $U_{0}(x) \equiv 0$ and that $p(0, y) \equiv 0$. If the liability scheme rewarded a driver in expectation for selecting $x=x_{i}>0$, then type $i=0$ individuals would start driving. This action leads to an increase in the cost of accidents; it must be inefficient. Further, it imposes an increased cost on the bicyclists who now must pay for accidents with type $i=0$ drivers. There is no reason to believe that our incentive scheme would continue to encourage cyclists to choose the appropriate action levels. Of course, we could explicitly include a fixed number of type 0 agents into our model and use Proposition 1 to derive a liability rule in which these agents take the efficient action level. This modification does not solve our problem. If type 0 agents must be paid in order not to drive, then there will be further entry of this type of agents. In the extended framework where the number of participants is endogenous, the requirement that expected damages be non-negative follows if we demand that 'disinterested' (type 0 ) parties do not participate in the activity.

Alternatively, we can enrich the model by allowing agents to control an unobservable variable, say, the level of care, that affects the probability of accidents. Assume that being more careful is costless and decreases the probability of accidents. Then it is efficient that all agents choose the highest possible care level because it minimizes expected accident costs. If the liability scheme gives rise to expected rewards, the agents to which these rewards apply will pick the lowest care level to increase the probability of being involved in accidents. Such behaviour is inefficient since it increases expected accident costs without generating additional utility. It seems worthwhile to consider liability rules that do not give rise to these additional incentive problems.

In order to characterize the action levels that can be implemented without expected rewards, we specialize our model. From now on, we assume that an action level $x \in[\underline{x}, \bar{x}]$ generates monetary utility $U_{i}(x)$ for injurer $i$ with $U_{i}(x)$ increasing in $x^{4}$ Injurers differ

4. If $x$ denotes a care level so that $U(x)$ is decreasing in $x$, let $\tilde{U}(x)=U(\bar{x}-x+x)$ and work with $\tilde{U}(\cdot)$ instead of $U(\cdot)$. We only use monotonicity of $U_{i}$ and $V_{j}$ in the proof of the lemma. The lemma remains true, with a small change in the argument, provided that $U_{i}$ and $V_{j}$ are bounded. 
in the increase in utility they obtain from raising the action level. Let injurers be ordered such that

$$
U_{i+1}(x)-U_{i}(x) \quad \text { is increasing in } x \quad \forall x \in[\underline{x}, \bar{x}], \quad i=1, \ldots, r-1,
$$

meaning that for all possible values of $x$, injurer $i$ has a lower increase in utility from an increase in $x$ than injurer $i+1$.

Victim $j, j=1, \ldots, r$, chooses an action level $y \in[y, \bar{y}]$ that yields monetary utility $V_{j}(y)$ with $V_{j}(y)$ increasing in $y$. Victims are also ordered according to the increase in utility from raising the action level, meaning that

$$
V_{j+1}(y)-V_{j}(y) \text { is increasing in } y \quad \forall y \in[\underline{y}, \bar{y}], \quad j=1, \ldots, r-1 .
$$

Under these assumptions we can completely characterize the set of actions that liability rules can implement. We then use the characterization result to determine which action levels can be implemented without expected rewards.

We first establish a preliminary result. We consider the restricted problem where injurers choose from an action vector $X^{*}$ and victims from an action vector $Y^{*}$. For each action $x_{k}^{*}$ we charge ex ante expected payments $M_{k}, k=1, \ldots, r$. Analogously, we charge $N_{l}$ for the action $y_{l}^{*}, l=1, \ldots, r$. Suppose that the expected payments $M_{k}, N_{l}, k$, $l=1, \ldots, r$, are such that injurer $i$ picks $x_{i}^{*}$ and victim $j$ picks $y_{j}^{*}, i, j=1, \ldots, r$, when they choose from the restricted sets. Moreover, suppose that the expected payments add up to total expected damages given $\left(X^{*}, Y^{*}\right)$.

We construct a liability rule $l(\cdot)$ defined on $[\underline{x}, \bar{x}] \times[y, \bar{y}]$ that implements the desired actions. Accordingly, we can let agents choose from the unrestricted action sets and implement $\left(X^{*}, Y^{*}\right)$. The rule $l(\cdot)$ satisfies $M_{i}=\sum_{j} l\left(x_{i}^{*}, y_{j}^{*}\right)$ and $N_{j}=$ $\sum_{i}\left[p\left(x_{i}^{*}, y_{j}^{*}\right)-l\left(x_{i}^{*}, y_{j}^{*}\right)\right]$. That is, we arrange things such that the liability rule gives rise to the expected payments $M_{i}, N_{j}, i, j=1, \ldots, r$, if the agents pick $\left(X^{*}, Y^{*}\right)$. If, e.g. a victim takes an action that is not included in $Y^{*}$, we "punish" him. Specifically, he does not choose $y \in\left(y_{j}^{*}, y_{j+1}^{*}\right)$, since doing so leads to the same expected payments as setting $y=y_{j+1}^{*}$ but less enjoyment because $V(\cdot)$ is strictly increasing. The Lemma allows us to focus on the construction of the expected payments $M_{i}, N_{j}, i, j=1, \ldots, r$, below. The proofs of the following statements are relegated to the Appendix.

Lemma. If there exist $M_{i}, i=1, \ldots, r$, and $N_{j}, j=1, \ldots, r$, such that

$$
\begin{gathered}
i \text { solves } \max _{k} U_{i}\left(x_{k}^{*}\right)-M_{k}, \quad k=1, \ldots, r, \\
j \text { solves } \max _{l} V_{j}\left(y_{l}^{*}\right)-N_{l}, \quad l=1, \ldots, r,
\end{gathered}
$$

and

$$
\sum_{i} M_{i}+\sum_{j} N_{j}=\sum_{i} \sum_{j} p\left(x_{i}^{*}, y_{j}^{*}\right.
$$

then there exists a liability rule $l(\cdot)$ that implements the action levels $\left(X^{*}, Y^{*}\right)$.

We may now completely characterize the set of actions that liability rules can implement.

Proposition 2. There exists a liability rule $l(\cdot)$ that implements the action levels $\left(X^{*}, Y^{*}\right)$ if and only if $X^{*}$ and $Y^{*}$ are non-decreasing. 
The requirement that action levels be non-decreasing is plainly necessary for implementation. Let us explain why it is also a sufficient condition. Because of the Lemma, we need only find a liability rule under which each agent prefers to take the action specified with his/her preferences over another type's action level. What matters to an agent is the expected damages associated with an action level. Assuming that everyone else does what the liability rule suggests, there are $2 r$ expected damages of the form $M_{i}=\sum_{j} l\left(x_{i}^{*}, y_{j}^{*}\right), i=1, \ldots, r$, and $N_{j}=\sum_{i}\left[p\left(x_{i}^{*}, y_{j}^{*}\right)-l\left(x_{i}^{*}, y_{j}^{*}\right)\right], j=1, \ldots, r$. However, the liability rule specifies $r^{2}$ numbers of the form $l\left(x_{i}^{*}, y_{j}^{*}\right), i, j=1, \ldots, r$. Since $r^{2} \geqq 2 r$ for $r \geqq 2$, it is not surprising that one can find liability rules that lead to arbitrary values for expected damages. Indeed, there exist liability rules that give rise to any expected payments $M_{i}$ and $N_{j}, i, j=1, \ldots, r$, such that $\sum_{i} M_{i}+\sum_{j} N_{j}=\sum_{i} \sum_{j} p\left(x_{i}^{*}, y_{j}^{*}\right)$. Hence, $2 r-1$ of the numbers $M_{i}$ and $N_{j}$ can be specified arbitrarily; the other value is determined by the equation $\sum_{i} M_{i}+\sum_{j} N_{j}=\sum_{i} \sum_{j} p\left(x_{i}^{*}, y_{j}^{*}\right)$. We use this flexibility to find expected damage payments that satisfy the $2(r-1)$ "adjacent" incentive constraints, that is, the constraints that guarantee that injurer $i$ prefers $x_{i}^{*}$ to $x_{i+1}^{*}$ and victim $j$ prefers $y_{j}^{*}$ to $y_{j+1}^{*}$. If these incentive constraints hold, then, by our assumption on preferences, so do the other incentive constraints. These arguments establish Proposition 2.

Proposition 3 characterizes action levels that can be implemented with non-negative expected payments.

Proposition 3. There exists a liability rule $I(\cdot)$ that implements the non-decreasing action levels $\left(X^{*}, Y^{*}\right)$ and $\left(M_{i}, N_{j}\right) \geqq 0 i, j=1, \ldots, r$, if and only if

$$
\sum_{i=1}^{r-1}(r-i)\left[U_{i}\left(x_{i+1}^{*}\right)-U_{i}\left(x_{i}^{*}\right)\right]+\sum_{j=1}^{r-1}(r-j)\left[V_{j}\left(y_{j+1}^{*}\right)-V_{j}\left(y_{j}^{*}\right)\right] \leqq \sum_{i} \sum_{j} p\left(x_{i}^{*}, y_{j}^{*}\right)
$$

An explanation of (5) is as follows. In order to implement action levels $\left(X^{*}, Y^{*}\right)$, expected damage payments must increase fast enough to ensure $U_{i}\left(x_{i}^{*}\right)-M_{i} \geqq$ $U_{i}\left(x_{i+1}^{*}\right)-M_{i+1}$. Consequently,

$$
\begin{gathered}
M_{2} \geqq U_{1}\left(x_{2}^{*}\right)-U_{1}\left(x_{1}^{*}\right), \\
M_{3} \geqq U_{1}\left(x_{2}^{*}\right)-U_{1}\left(x_{1}^{*}\right)+U_{2}\left(x_{3}^{*}\right)-U_{2}\left(x_{2}^{*}\right), \ldots, M_{r} \geqq \sum_{i=1}^{r-1}\left[U_{i}\left(x_{i+1}^{*}\right)-U_{i}\left(x_{i}^{*}\right)\right] .
\end{gathered}
$$

It follows from algebraic manipulation that the left-hand side of $(5)$ is a lower bound on the total expected damage payments that can be made without using expected rewards. But the total amount of damage payments cannot exceed $\sum_{i} \sum_{i} p\left(x_{i}^{*}, y_{j}^{*}\right)$. Expression (5) follows.

Since the left-hand side of (5) is bounded above, (5) holds for all action levels $(X, Y)$ if damages are uniformly high. It is also apparent that (5) holds if the action levels are constant, i.e. $x_{i}$ independent of $i$ and $y_{j}$ independent of $j$, because in this case the left-hand side of (5) is equal to zero. If we confine attention to restricted optimal action levels, then we can find a sufficient condition for implementing this type of actions that depends only on $p(\cdot)$ and not on preferences. If $\left(X^{*}, Y^{*}\right)$ is restricted optimal, then

$$
\begin{aligned}
& \sum_{i=1}^{r-1}(r-i)\left(U_{i}\left(x_{i+1}^{*}\right)-U_{i}\left(x_{i}^{*}\right)\right)+\sum_{j=1}^{r-1}(r-j)\left(V_{j}\left(y_{j+1}^{*}\right)-V_{j}\left(y_{j}^{*}\right)\right) \\
& \leqq \sum_{i=1}^{r-1}(r-i)\left[\sum_{j}\left(p\left(x_{i+1}^{*}, y_{j}^{*}\right)-p\left(x_{i}^{*}, y_{j}^{*}\right)\right)\right] \\
&+\sum_{j=1}^{r-1}(r-j)\left[\sum_{i}\left(p\left(x_{i}^{*}, y_{j+1}^{*}\right)-p\left(x_{i}^{*}, y_{j}^{*}\right)\right)\right] \\
&= 2 \sum_{i} \sum_{j} p\left(x_{i}^{*}, y_{j}^{*}\right)-r\left[\sum_{j} p\left(x_{1}^{*}, y_{j}^{*}\right)+\sum_{i} p\left(x_{i}^{*}, y_{1}^{*}\right)\right] .
\end{aligned}
$$


Consequently, (5) holds whenever

$$
\sum_{i} \sum_{j} p\left(x_{i}^{*}, y_{j}^{*}\right) \leqq r\left[\sum_{j} p\left(x_{1}^{*}, y_{j}^{*}\right)+\sum_{i} p\left(x_{i}^{*}, y_{1}^{*}\right)\right] \text {. }
$$

Condition (6) holds if $p(\cdot)$ is additively separable or if $\inf _{x \cdot y} p(x, y) \geqq \frac{1}{2} \sup _{x, y} p(x, y) .^{5}$

\section{RELATION TO OTHER WORK}

Several other authors have studied the problem of designing efficient liability rules. In this section we will relate our results to this literature.

Posner ((1986), pp. 176-177) has argued that there are "powerful reasons" not to allow for punitive damages in tort cases. The example in Section III demonstrates that this advice does not apply when victims and injurers have different preferences over action levels. Punitive damages provide the flexibility needed to create rules that fully internalize the costs of participating in risky activities. Shavell ((1987), pp. 159-163) discusses other situations where punitive damages may be optimal.

To implement the first-best allocation $\left(X^{*}, Y^{*}\right)$, the literature suggests (see Landes and Posner (1987), pp. 123-131, Shavell (1987), pp. 73-104) the application wherever possible of the following negligence rule using the incremental Learned Hand formulation

$$
l\left(U_{1}^{\prime}(x), \ldots, U_{r}^{\prime}(x), p_{x}\left(x, y_{1}^{*}\right), \ldots, p_{x}\left(x, y_{r}^{*}\right), x, y\right)= \begin{cases}0, & \text { if } U_{i}^{\prime}(x) \geqq \Sigma_{j} p_{x}\left(x, y_{i}^{*}\right) \\ p(x, y), & \text { otherwise. }\end{cases}
$$

In case of an accident, an injurer is not deemed liable if her marginal utility from the action is greater than or equal to the marginal expected damage she thereby causes; otherwise, the injurer is strictly liable. Assume $U_{i}(\cdot)$ is concave, $i=1, \ldots, r$, and $p(\cdot)$ strictly convex and increasing. Suppose victims pick $Y^{*}$. Given this discontinuous negligence rule, it is an optimal strategy for injurer $i$ to choose the socially efficient action level $x_{i}^{*}$ generating the highest utility among the action levels that involve no damage payments for her. Given the injurers' behaviour, victims bear the entire accident costs. That is, when choosing his action victim $j$ takes into account all of the adverse effects of his behaviour and accordingly picks the socially optimal level $y_{j}^{*}$. Thus, the negligence rule using the incremental Learned Hand formulation decentralizes the first-best optimum $\left(X^{*}, Y^{*}\right)$.

The negligence rule using the incremental Learned Hand formulation requires that in case of an accident a court can ascertain each injurer's utility function. Furthermore, this rule implicitly defines different due action (care) levels for different injurers. To return to our car driver/bicyclist example, it would allow a saleswoman to drive up to $100 \mathrm{~m}$.p.h. without being liable whereas a housewife is strictly liable if her speed exceeds 20 m.p.h. Such a rule obviously raises problems with respect to the equal protection clause. $^{6}$

We have shown that we can implement the first-best allocation by a liability rule of the form $l(x, y)$. Our rule does not require that courts can ascertain utility functions nor does it raise problems regarding equal protection, because it equally applies to all individuals.

5. See Emons (1990) for an alternative proof that we can implement the efficient action levels if $p(\cdot)$ is additively separable. Green (1976) also analyses the additively separable case. His statement (p. 573) that rules which allow for the sharing of costs cannot, by their very nature, impose the full marginal impact on each group and therefore are not first-best optimal is not generally true. In the additively separable case which Green considers we can always implement the first-best without using expected rewards.

6. Perhaps the major problem with individually tailored legal systems is not the constitutional one of equal protection so much as the tradition of what counts as a relevant difference when applying the principle that like cases should be treated alike. 
If it is not possible to apply the incremental Learned Hand rule, the literature suggests (see, e.g. Diamond (1974), Posner (1986), pp. 151-152, Shavell (1987), pp. 86-89) using a negligence rule combined with the reasonable man/woman standard. Take some average (in legal parlance "reasonable") injurer and determine her socially optimal action level which we will denote by $\hat{x}$. Define $\hat{x}$ as the due action (care) level of the negligence rule

$$
l(x, y)= \begin{cases}0, & \text { if } x \leqq \hat{x} ; \\ p(x, y), & \text { otherwise } .\end{cases}
$$

If this rule works in the desired way, all injurers choose the due action level $\hat{x}^{7}$ This causes an inefficiency because injurers below the average engage in an action that is too high whereas injurers above the average engage in one that is too low compared to the social optimum. Since all injurers choose $\hat{x}$, victims bear the entire accident cost and pick action levels that are efficient given the injurers' inefficient choice.

The reasonable-man rule thus implements an inefficient allocation. Our rule implements the first-best $\left(X^{*}, Y^{*}\right)$ without expected punitive damages and expected rewards if (5) holds. Thus, if total damages are large, the reasonable man rule cannot maximize social welfare. Emons (1990) shows that the reasonable man rule can always be improved upon even if (5) is not satisfied and actual punitive damages are not allowed.

Let us finally discuss the informational requirements of the different liability rules. The rule described in Section IV, the negligence rule, and the reasonable-man standard have the same informational requirements. These rules require knowledge of the damage technology, but do not depend explicitly on the preferences of the agents in the economy. All of the rules require the planner to know the utility functions in the economy in order to compute the efficient action levels. The efficient actions enter explicitly in the formula for the liability rules in Section IV. Similarly, in the case of the negligence rule, the planner must know preferences in order to compute the efficient due action level. The reasonable-man rule has the same informational requirements as the negligence rule. To determine the reasonable-man standard a planner needs to know the preferences of each type of agent and the damage function. (See Shavell (1987), pp. 86-89.) The same can be said for the rules that we describe in Section V. We need to know preferences in order to determine what action levels to implement. Further, and unlike the other rules discussed thus far, the liability rules themselves explicitly depend on the utility function of the agents in the economy. None of these rules requires the knowledge needed to implement the incremental Learned Hand rule. In this case, the judge must know the preferences of each agent, instead of the distribution of preferences in the economy.

\section{CONCLUSIONS}

We have derived a liability rule that allows us to implement the efficient allocation of the action levels. We have furthermore completely characterized the set of action levels that liability rules can implement with and without the restriction that no party should expect to benefit from an accident.

Our results have the following implications. First, it is punitive damages that allow us to implement any non-decreasing action levels in general. Second, if total damages are large, we can implement the action levels without raising new incentive problems. Third, the negligence rule using the reasonable man standard is not optimal if damages are large, because we can implement the first-best allocation in this case without relying on rules that raise the knotty conflict of efficiency versus equal protection.

7. If $\hat{x}$ is not chosen high enough, then some injurer may pick $x>\hat{x}$. 
The assumption that all agents in the economy are risk-neutral allows us to abstract from the effects of liability rules on the allocation of risks. If the agents are risk-averse, a tradeoff between providing incentives for choosing appropriate private actions and efficient risk-sharing arises. Nevertheless, following Landes and Posner ((1987), pp. 56-58), the major task of accident law is to provide the correct incentives. Studying the risk-neutral case is thus a useful first step towards a more general analysis.

\section{APPENDIX}

Proof of the lemma. Construct $l\left(x_{i}^{*}, y_{j}^{*}\right)$ to satisfy

$$
\sum_{j} l\left(x_{i}^{*}, y_{j}^{*}\right)=M_{i} \text { and } \sum_{i} l\left(x_{i}^{*}, y_{j}^{*}\right)=\sum_{i} p\left(x_{i}^{*}, y_{j}^{*}\right)-N_{j} .
$$

Finding values of $l\left(x_{i}^{*}, y_{j}^{*}\right)$ to solve these equations provided (4) holds is equivalent to finding a feasible point for a transportation problem. This problem is feasible. See, e.g. Hillier and Lieberman ((1986), pp. 184-212).

Now define $l(x, y)$ by

$$
l(x, y)= \begin{cases}l\left(x_{1}^{*}, y_{j}^{*}\right), & \text { if } x \in\left[\underline{x}, x_{1}^{*}\right], y=y_{j}^{*}, j=1, \ldots, r ; \\ l\left(x_{i}^{*}, y_{j}^{*}\right), & \text { if } x \in\left(x_{i-1}^{*}, x_{i}^{*}\right], i=2, \ldots, r, \\ l\left(x_{r}^{*}, y_{j}^{*}\right)+(1 / r)\left[U_{r}(\bar{x})-U_{r}\left(x_{r}^{*}\right)\right], & y=y_{j}^{*}, j=1, \ldots, r ; \\ p\left(x_{i}^{*}, y\right)-\left[p\left(x_{i}^{*}, y_{1}^{*}\right)-l\left(x_{i}^{*}, y_{1}^{*}\right)\right], & \text { if } x \in\left(x_{r}^{*}, \bar{x}\right], y=y_{j}^{*}, j=1, \ldots, r \\ p\left(x_{i}^{*}, y\right)-\left[p\left(x_{i}^{*}, y_{j}^{*}\right)-l\left(x_{i}^{*}, y_{j}^{*}\right)\right], & \text { if } y \in\left[y, y_{1}^{*}\right], x=x_{i}^{*}, i=1, \ldots, r ; \\ p\left(x_{i}^{*}, y\right)-\left[p\left(x_{i}^{*}, y_{r}^{*}\right)-l\left(x_{i}^{*}, y_{r}^{*}\right)\right]- & \text { if } y \in\left(y_{j-1}^{*}, y_{j}^{*}\right], j=2, \ldots, r, \\ (1 / r)\left[V_{r}(\bar{y})-V_{r}\left(y_{r}^{*}\right)\right], & x=x_{i}^{*}, i=1, \ldots, r ; \\ 0, & \text { if } y \in\left(y_{r}^{*}, \bar{y}\right], x=x_{i}^{*}, i=1, \ldots, r\end{cases}
$$

Suppose victims pick $Y^{*}$ and consider $x \in\left[\underline{x}, x_{r}^{*}\right]$. The expected payments $\sum_{j} l\left(\cdot, y_{j}^{*}\right)$ are constant over the intervals $\left[x, x_{1}^{*}\right],\left(x_{i-1}^{*}, x_{i}^{*}\right], i=2, \ldots, r$. Since $U_{i}$ is increasing in $x, i=1, \ldots, r$, only the values of $\left(x_{1}^{*}, \ldots, x_{r}^{*}\right)$ can be utility-maximizing choices for injurers. Yet, $\sum_{j} l\left(x_{i}^{*}, y_{j}^{*}\right)=M_{i}$ and

$$
i \text { solves } \max _{k}\left[U_{i}\left(x_{k}^{*}\right)-M_{k}\right], \quad k=1, \ldots, r \text {. }
$$

Consider now $x \in\left(x_{r}^{*}, \bar{x}\right]$. Then we have

$$
U_{r}(x)-\sum_{j} l\left(x, y_{j}^{*}\right)=U_{r}(x)-U_{r}(\bar{x})+U_{r}\left(x_{r}^{*}\right)-M_{r} \leqq U_{r}\left(x_{r}^{*}\right)-M_{r}
$$

Hence, injurer $r$ prefers $x_{r}^{*}$ to any action level $x \in\left(x_{r}^{*}, \bar{x}\right]$. Since $U_{r}(x)-U_{i}(x)$ is increasing, $i=1, \ldots, r-1$, this implies that injurer $i$ also prefers $x_{i}^{*}$ to any action level $x \in\left(x_{r}^{*}, \bar{x}\right]$. Thus, given victims pick $Y^{*}$, injurers choose $X^{*}$ under the liability rule $I(\cdot)$. A similar argument demonstrates that given injurers pick $X^{*}$, victims choose $Y^{*}$. $\|$

Proof of Proposition 2. First assume that $\left(X^{*}, Y^{*}\right)$ can be implemented with the liability rule $l(\cdot)$. It follows from (2) that

$$
U_{i+1}\left(x_{i+1}^{*}\right)-U_{i+1}\left(x_{i}^{*}\right) \geqq \sum_{j}\left[l\left(x_{i+1}^{*}, y_{j}^{*}\right)-I\left(x_{i}^{*}, y_{j}^{*}\right)\right] \geqq U_{i}\left(x_{i+1}^{*}\right)-U_{i}\left(x_{i}^{*}\right),
$$

and similarly from (3) that

$$
V_{j+1}\left(y_{j+1}^{*}\right)-V_{j+1}\left(y_{j}^{*}\right) \geqq V_{j}\left(y_{j+1}^{*}\right)-V_{j}\left(y_{j}^{*}\right) .
$$

However, by our assumption $U_{i+1}(x)-U_{i}(x)$ and $V_{j+1}(y)-V_{j}(y)$ are increasing. Therefore, $X^{*}$ and $Y^{*}$ are non-decreasing.

To prove that any non-decreasing $X^{*}$ and $Y^{*}$ can be implemented, we construct expected damage functions $\left(M_{i}, N_{j}\right) i, j=1, \ldots, r$, that satisfy the conditions of the lemma.

Consider the sequence $M_{i}(m)$ defined by

$$
\begin{aligned}
& M_{1}(m)=m, \\
& M_{i}(m)=U_{i-1}\left(x_{i}^{*}\right)-U_{i-1}\left(x_{i-1}^{*}\right)+M_{i-1}(m) \text { for } i=2, \ldots, r .
\end{aligned}
$$


Let $i \leqq l \leqq k$. We have

$$
\begin{aligned}
U_{k}\left(x_{k}^{*}\right)-U_{k}\left(x_{i}^{*}\right) & =\sum_{i=i}^{k-1}\left[U_{k}\left(x_{i+1}^{*}\right)-U_{k}\left(x_{i}^{*}\right)\right] \geqq \sum_{i-i}^{k-1}\left[U_{l}\left(x_{l+1}^{*}\right)-U_{1}\left(x_{i}^{*}\right)\right] \\
& =M_{k}(m)-M_{i}(m) \geqq \sum_{i=i}^{k-1}\left[U_{i}\left(x_{l+1}^{*}\right)-U_{i}\left(x_{i}^{*}\right)\right] \\
& =U_{i}\left(x_{k}^{*}\right)-U_{i}\left(x_{i}^{*}\right),
\end{aligned}
$$

where the inequalities follow because $U_{k}(x)-U_{i}(x) \geqq U_{k}\left(x^{\prime}\right)-U_{i}\left(x^{\prime}\right)$ wherever $k>i$ and $x \geqq x^{\prime}$ and the second equality follows from (7). The expression above implies that

$$
U_{k}\left(x_{k}^{*}\right)-M_{k}(m) \geqq U_{k}\left(x_{i}^{*}\right)-M_{i}(m)
$$

and

$$
U_{i}\left(x_{i}^{*}\right)-M_{i}(m) \geqq U_{i}\left(x_{k}^{*}\right)-M_{k}(m)
$$

Therefore, the expected payments $M_{i}(m), i=1, \ldots, r$ solve the injurers' incentive problem (2) for all $m$. Similarly, the sequence $N_{j}(n)$ defined by

$$
\begin{aligned}
& N_{1}(n)=n, \\
& N_{j}(n)=V_{j-1}\left(y_{j}^{*}\right)-V_{j-1}\left(y_{j-1}^{*}\right)+N_{j-1}(n) \text { for } j=2, \ldots, r
\end{aligned}
$$

solves the victims' incentive problem (3) for all $n$.

Now notice that

$$
\sum_{i} M_{i}(m)=\Sigma_{i} M_{i}(0)+m r
$$

and

$$
\sum_{j} N_{j}(n)=\sum_{j} N_{j}(0)+n r
$$

Therefore, given any $m$, there is a unique $n$ such that

$$
\sum_{i} M_{i}(m)+\sum_{j} N_{j}(n)=\sum_{i} \sum_{j} p\left(x_{i}^{*}, y_{j}^{*}\right) .
$$

The proposition follows from the lemma. \|

Proof of Proposition 3. A straightforward computation confirms that (5) is equivalent to

$$
\sum_{i=1}^{r} M_{i}(0)+\sum_{j=1}^{r} N_{j}(0) \leqq \sum_{i} \sum_{j} p\left(x_{i}^{*}, y_{j}^{*}\right)
$$

where $M_{i}(0)$ and $N_{j}(0)$ are defined in (7) and (8). If $(9)$ holds, then we can implement $\left(X^{*}, Y^{*}\right)$ using expected payments $M_{i}(0)$ and $N_{j}(n)$ where

$$
n=1 / r\left[\sum_{i} \sum_{j} p\left(x_{i}^{*}, y_{j}^{*}\right)-\sum_{i=1}^{r} M_{i}(0)-\sum_{j=1}^{r} N_{j}(0)\right] \geqq 0 .
$$

Hence, $N_{j}(n) \geqq N_{1}(n)=n \geqq 0$ and $M_{i}(0) \geqq M_{1}(0)=0, i, j=2, \ldots, r$.

Conversely, note that for any expected payments that implement $\left(X^{*}, Y^{*}\right), M_{\mathrm{i}}^{\prime}, N_{j}^{\prime}$, we must have

$$
\begin{gathered}
M_{i-1}^{\prime}-M_{j}^{\prime} \leqq U_{i-1}\left(x_{i-1}^{*}\right)-U_{i-1}\left(x_{i}^{*}\right)=M_{i-1}(0)-M_{i}(0), \\
N_{j-1}^{\prime}-N_{j}^{\prime} \leqq V_{j-1}\left(y_{j-1}^{*}\right)-V_{j-1}\left(y_{j}^{*}\right)=N_{j-1}(0)-N_{j}(0),
\end{gathered}
$$

and

$$
\sum_{i} M_{i}^{\prime}+\sum_{j} N_{j}^{\prime}=\sum_{i} \Sigma_{j} p\left(x_{i}^{*}, y_{j}^{*}\right)
$$

Consequently, if $M_{1}^{\prime}$ and $N_{1}^{\prime} \geqq 0$,

$$
M_{i}(0) \leqq M_{i}^{\prime} \quad \text { and } \quad N_{j}(0) \leqq N_{j}^{\prime}, \quad i, j=1, \ldots, r .
$$

Conditions (10) and (11) imply (9) and complete the proof. \|

Acknowledgement. We have benefited from comments of Claude d'Aspremont, Helmut Bester, Andreas Blume, Susan Dwyer-Shick, Roger Guesnerie, Martin Hellwig, Roger Myerson, Tom Palfrey, Jonathan Pool, Steven Shavell, and two referees. For Emons, financial support by the Deutsche Forschungsgemeinschaft and the Schweizerischer Nationalfonds, and the hospitality of the Department of Economics at U.C. San Diego and The CentER for Economic Research, Tilburg University are gratefully acknowledged. For Sobel, financial support from the NSF and Sloan Foundation is gratefully acknowledged. 


\section{REFERENCES}

d'ASPREMONT, C. and GÉRARD-VARET, L. A. (1979), "Incentives and Incomplete Information", Journal of Public Economics, 11, 25-45.

DIAMOND, P. A. (1974), "Single Activity Accidents", Journal of Legal Studies, 3, 107-164.

EMONS, W. (1990), "Efficient Liability Rules for an Economy with Non-identical Individuals", Journal of Public Economics, 42, 89-104.

GREEN, J. (1976), "On the Optimal Structure of Liability Laws", Bell Journal of Economics, 7, 553-574.

HILLIER, F. S. and LIEBERMAN, G. J. (1986) Introduction to Operations Research, 4th ed. (Oakland: Holden-Day).

LANDES, W. M. and POSNER, R. A. (1987) The Economic Structure of Tort Law (Cambridge, Mass: Harvard University Press).

MA, C. T., MOORE, J. and TURNBULL, S. (1988), "Stopping Agents from 'Cheating'", Journal of Economic Theory, 46, 355-372.

MOORE, J. and REPULLO, R. (1988), "Subgame Perfect Implementation", Econometrica, 56, 1191-1220.

MYERSON, R. B. (1985), "Bayesian Equilibrium and Incentive-Compatibility: An Introduction", in Hurwicz, L., Schmeidler, D. and Sonnenschein, H. (Eds.) Social Goals and Social Organization, Essays in Memory of Elisha A. Pazner (Cambridge: Cambridge University Press), pp. 229-259.

POSNER, R. A. (1986) Economic Analysis of Law, 3rd ed. (Boston: Little, Brown).

SHAVELL, S. (1980), "Strict Liability versus Negligence", Journal of Legal Studies, 9, 1-25.

SHAVELL, S. (1987) Economic Analysis of Accident Law (Cambridge, Mass: Harvard University Press). 